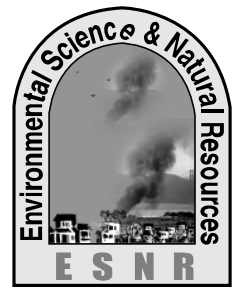

\title{
Contribution of Farming Enterprises of the Small Farmers towards Household Food Security
}

\author{
H. Kobir, M. Z. Rahman ${ }^{1}$, M. S. Islam ${ }^{2}$, N. Sultana ${ }^{2}$ and M. A. A. Al-Musa ${ }^{3}$ \\ AEO, Dept. of Agricultural Extension, Ministry of Agriculture, \\ ${ }^{1}$ Professor, Dept. of Agricultural Extension, Bangladesh Agricultural University, Mymemsingh \\ ${ }^{2}$ Research Officer, (Agriculture), Bangladesh Water Development Board
}

${ }^{3}$ IFDC, Bangladesh

\begin{abstract}
The study was to determine the contribution of farming enterprises of small farmers towards household food security and explore relationship with their selected characteristics. Besides, attempts were also made to ascertain the problems faced by the small farmers in achieving household food security. The highest proportion $(57 \%)$ of the small farmers was in medium while $27 \%$ of them were in low category in achieving household food security. Only $44.78 \%$ of annual dietary needs of the family were fulfilled from the farming enterprises of the small farmers and more than half of the requirements remained unsatisfied. Among the four sectors of farming enterprises, the highest proportion $(41.70 \%)$ was contributed by crops alone. Among ten characteristics of the small farmers, farm size and annual family income were positively correlated but family size, annual dietary needs of the family and practiced cropping intensity showed negative relationship with the contribution of farming enterprises towards household food security. The rest characteristics viz. age, education, credit received daily time allocation in farm works and exposure to farming information of the respondents showed insignificant correlation with their achievement of contribution of their farming enterprises towards the household food security. The major problems faced by the small farmers in achieving household food security were inadequate land for farming, inadequate training facilities, lack of contact with communication media, insufficient credit and lack of knowledge of different aspects of improved farming enterprises.
\end{abstract}

Key words: Small farmers, Household food security, Farming enterprises

\section{Introduction}

Food is a basic human need and plays a crucial role in the agro based economy of Bangladesh, where a large proportion of the income of population is allocated to food. Bangladesh has made steady progress in food production and enhanced its capacity for commercial exports, food security is still a major problem because of the lack of purchasing power and thus of access to food. A sizeable proportion of the rural population is landless and depends on casual labor for livelihood. Due to the seasonal nature of agricultural employment and livelihood employment opportunities in the nonagriculture sector, millions suffer from chronic and transitory food security. Household food security has been defined by Food and Agriculture Organization of the United Nations (FAO, 1995) as the economic, physical and social capacity of a household to continually provide family members with sufficient food for individual bodily needs without threats of shortage. This requires not just enough food to go around. It requires that people have ready access to food that they have an "entitlement" to food, by growing it for themselves, by buying it or by taking advantage of a public food distribution system. The availability of food is thus a necessary condition of security, but not a sufficient one. Three dimensions of the FAO household food security program are: availability, access and stability. Small farmers face particular constraints as farmers, processors and marketers of food based enterprises. Most of them cultivate others land as sharecropping on which they have little authority to make decisions. They cannot diversify their lands for adopting various farming enterprises and intensify through increasing the number of crops in the same land per cropping year. Consequently, they harvest yield below the expected level. Poverty, vulnerability, physical weakness, malnutrition etc., thus, become their daily companion. This notion of small farmers is a regular common picture in the rural Bangladesh. However, they operate different farming enterprises like rice, wheat, jute, potato, spices, livestock, fruits etc. within a limited range as subsistence type of agriculture. Total family expenses are fulfilled with the farming outputs. Finally, household food security paradigm remains far from consideration. In this context, the contribution of farming enterprises of the small farmers to the household food security could be worthy to assess.

\section{Methodology}

The study was conducted in three villages namely Biltakapora, Bildhamu and Bakshadangi of Narua union under Baliakandhi upazila of Rajbari district were randomly selected. Out of 456 small farmers of these three villages 120 small farmers $(26 \%$ of total population) were selected randomly. Data were collected through direct interview from the small farmers during 05 August to 20 September 2007. Contribution of farming enterprises of small farmers towards household food security was the dependent variable and the selected ten socio-personal characteristics of the small farmers constituted the independent variables of the study.

\section{Dependent variable measurement}

Contribution of farming enterprises towards household food security $(\%)=$ Total calorie obtained 
from farm produces per year/Total calorie needed by family members per year

Total calorie obtained from farm produces per year was determined with the help of a list of energy (kcal) content in $100 \mathrm{~g}$ of different food items (Meyer, 2004). Not all the farming enterprises could be converted into energy (kcal) using this list. Problem arose when it was found that some part of the farm produces were sold out by the respondents and some item like jute and tree could not be directly converted into energy (kcal). These are obviously cash item i.e. directly related to monetary return rather than calorific value. It was, therefore, inevitable to find out a conversion factor to be used to convert cash items into energy ( $\mathrm{kcal})$. Cash energy conversion factor $=$ Total calorific value of the produces/ Total monetary value of the produces

\section{Independent variables measurement}

Age of a respondent was measured in terms of years from birth to the time of interview which was found on the basis of response (Azad, 2003). A unit score was assigned for each year of one's age. Education was measured in terms of one's year of schooling. One score was given for passing each level in an educational institution (Amin, 2004). For example, SSC examination score was given as 10 while a respondent did not know how to read and write his educational score was given as ' 0 '. Family size was measured by the total number of members in the family of a respondent. The family members included family head and other dependent members who lived and ate together while a unit score was assigned for each member (Khan, 2004). Annual dietary need of the family was measured on the basis of the body weight of the family members. It was assumed that 40 calories of energy needed per kilogram body weight per day (Kleiner, 2006). Dietary needs of the family per annum were then calculated from the total body weights of all the family members at the rate of 40 calorie per day per kilogram body weight. Finally, one unit score was given for every thousand kilocalorie energy. Farm size of a respondent referred to the total area of land on which his family carried out farming operation, the area being in terms of full benefit to the family. Annual income referred to the total financial return of a household from farm (crops, livestock, poultry and fish) and non-farm sources (business, job, remittance and others) in one year and was expressed in Taka. Credit received of a respondent was measured in terms of the amount of money received by his family members as loan from different sources. A score of one was given for each thousand taka (Akter, 2003). Daily time allocation referred to how much time is spent per day by the small farmers in farm activities and it was expressed in terms of hour per day. Besides, attempt was made to know the time allocation in non-farm activities, like household work, social activities, rest, sleep and others (Dulayapach, 1990). Exposure to farming information was scored against four-point rating scale as 0 for 'not at all' 1 for 'rarely' 2 for 'occasionally' and 3 for 'regularly' (Hasan, 2006). Net cropped area was calculated by adding the single cropped area (SCA), double cropped area (DCA), triple cropped area (TCA) and quadruple cropped area (QCA). A four point rating scale was used for computing the problem score of a respondent. For each problem score of ' 3 ', ' 2 ', ' 1 ' and ' 0 ' was assigned to indicate extent of problem as 'high', 'medium', 'low' and 'not at all' respectively.

\section{Results and Discussion}

Basic statistical values of the independent variables of the respondents as presented in Table 1 where age of the small farmers ranged from 22 to 60 years with a mean of 38.21 years and SD of 7.10. However, based on their age the small farmers were classified into three categories as young, middle-aged and old. Table 1 revealed that the middle aged was $71.7 \%$, young was $15.8 \%$ and the rest $12.5 \%$ were old. It should be mentioned that most of the young people did not get the authority of controlling the family rather the middle-aged people were as the family heads. The level of education of the respondent small farmers ranged from $0-10$, the average being 4.52 with a SD of 3.16. According to national standard of classification, among the respondent small farmers, $13.3 \%$ were illiterate, $50 \%$ had education at primary level, and $36.7 \%$ had education at secondary level which indicated that half of the respondent small farmers secured primary level. It was logical because only $12.5 \%$ of the respondents were old age and education was generally negatively correlated with age. This study assumed that small farmers having higher education were more progressive and innovative than those of illiterate and they could adopt numerous farming enterprises to secure their household food security.

The number of family members of the small farmers ranged from 2 to10. The mean was 4.75 with the SD 1.37. Based on the family size score, $49.2 \%$ had small family size while $44.1 \%$ was medium and $6.7 \%$ had large (Table 1). Findings reveal that the family size of the people is being decreased day by day in Bangladesh. The level of annual dietary needs of the family of the small farmer respondents thousand kilocalorie ranged from 1.74 to 6.81 . The mean was 3.48 thousand $\mathrm{kcal}$ and the SD being 1.03 thousand $\mathrm{kcal}$. According to the observed value of the annual dietary needs of the family, majority $(60 \%)$ needed medium amount of calories, $32.5 \%$ needed low amount and the rest $7.5 \%$ needed high amount of calories. Farm size of the small farmers ranged from 0.2 to 0.96 ha having an average of 0.43 ha and SD of 0.17 ha. The highest proportion $(63.3 \%)$ of the small farmers had 0.2 to 0.45 ha land area, $30.9 \%$ had 0.46 to 0.7 ha 
and the rest $5.8 \%$ had 0.71 to 0.96 ha land area. Based on the observed information, it is very much clear that most of them had fewer amounts of land holdings than the average farm size of the small farmers. The range of the annual family income varied from 31 to 135 thousand taka with a mean of 71.24 thousand taka and SD of 21 thousand taka (Table 1). Among the three categories, the highest proportion of the respondents $(69.2 \%)$ had medium annual family income while 20.8 and $10 \%$ had low and high annual family income, respectively. Findings reveal that most $(90 \%)$ of the respondents had low to medium annual family income. So their annual family income remains low to medium. The score of credit received by the respondents ranged from 0 to 905 thousand taka with a mean of 13.87 thousand taka and SD of 82.34 thousand taka. On the basis of credit received, the highest proportion $(95.8 \%)$ of the small farmers had low credit received while $3.4 \%$ had medium credit received and the rest $0.8 \%$ of them had high credit received. Daily time allocation in farm works ranged was 1 to 10 hours per day while the average mean was 6.85 with a SD of 2.48 hours per day which showed data showed most of the small farmers $(63.3 \%)$ spent more than six hours a day in farm works, while 29.2 and $7.5 \%$ of them allocated medium and short time for farm works respectively.
The source of family income and earnings of the small farmers was mainly their small farms and they want to fulfill family requirement from their small farming enterprises by work hard for longer period. The observed score of exposure to farming information of the small farmers ranged from 3 to 18 against a possible range of 0 to 30 . The average score of the farmers was 9.08 with a SD of 3.08 (Table 1). The respondent farmers were classified into three categories where the highest proportion $(69.2 \%)$ of the respondents had less exposure to farming information and only $30.8 \%$ of the respondents fell in moderate exposure to farming information category

The practiced cropping intensity of the small farmers ranged from 200 to $300 \%$ with average and standard deviation of 246.87 and 23.17 respectively (Table 1). The small farmers were classified into three categories based on their practiced cropping intensity where half $(45.8 \%)$ of the respondents cultivated their lands to have a medium cropping intensity, 31.7 and $22.5 \%$ of them cultivated to have low and high cropping intensity respectively. The farmers with small farm holdings have to produce more number of crops from the same land in a year to provide foods for the family members.

Table 1. Characteristics profile of the respective small farmers

\begin{tabular}{|c|c|c|c|c|c|c|c|}
\hline \multirow{2}{*}{ Characteristics (measuring unit) } & \multicolumn{2}{|c|}{ Range } & \multicolumn{3}{|l|}{ Respondents } & \multirow{2}{*}{ Mean } & \multirow{2}{*}{ SD } \\
\hline & Possible & Observed & Category & No. & $\%$ & & \\
\hline \multirow[t]{3}{*}{ Age (year) } & - & $22-60$ & Young $(\leq 30)$ & 19 & 15.8 & & \\
\hline & & & Middle-aged (31-45) & 86 & 71.7 & 38.21 & 7.10 \\
\hline & & & Old $(>45)$ & 15 & 12.5 & & \\
\hline \multirow[t]{3}{*}{ Education (years of schooling) } & - & $0-10$ & Illiterate $(0)$ & 16 & 13.3 & & \\
\hline & & & Primary education (1-5) & 60 & 50.0 & 4.52 & 3.16 \\
\hline & & & Secondary education (6-10) & 44 & 36.7 & & \\
\hline \multirow[t]{3}{*}{ Family size (number) } & - & $2-10$ & Small family $(\leq 4)$ & 59 & 49.2 & & \\
\hline & & & Medium family (5-6) & 53 & 44.1 & 4.75 & 1.37 \\
\hline & & & Large family $(>6)$ & 8 & 6.7 & & \\
\hline \multirow[t]{3}{*}{ Annual dietary needs of the family (' 000 ' kcal) } & - & $1.74-6.81$ & Low $(<3)$ & 39 & 32.5 & & \\
\hline & & & Medium (3-5) & 72 & 60.0 & 3.48 & 1.03 \\
\hline & & & High $(>5)$ & 9 & 7.5 & & \\
\hline \multirow[t]{3}{*}{ Farm size (ha) } & - & $0.20-0.96$ & $0.20-0.45$ ha & 76 & 63.3 & & \\
\hline & & & $0.41-0.70 \mathrm{ha}$ & 37 & 30.9 & 0.43 & 0.17 \\
\hline & & & $0.71-0.96 \mathrm{ha}$ & 7 & 5.8 & & \\
\hline \multirow{3}{*}{ Annual family income ('000’ Tk.) } & - & $31-135$ & Low $(\leq 50)$ & 25 & 20.8 & & \\
\hline & & & Medium (51-100) & 83 & 69.2 & 71.24 & 21.00 \\
\hline & & & High $(>100)$ & 12 & 10.0 & & \\
\hline \multirow[t]{3}{*}{ Credit received ('000’ Tk.) } & - & $0-905$ & Low $(\leq 20)$ & 115 & 95.8 & & \\
\hline & & & Medium (21-40) & 4 & 3.4 & 13.87 & 82.34 \\
\hline & & & $\operatorname{High}(>40)$ & 1 & 0.8 & & \\
\hline \multirow{3}{*}{ Daily time allocation in farm work (hour per day) } & - & $1-10$ & Low $(<3)$ & 9 & 7.5 & & \\
\hline & & & Medium (3-6) & 35 & 29.2 & 6.85 & 2.48 \\
\hline & & & High $(>6)$ & 76 & 63.3 & & \\
\hline \multirow[t]{2}{*}{ Exposure to farming information (score) } & $0-30$ & $3-18$ & Less $(\leq 10)$ & 83 & 69.2 & & \\
\hline & & & Moderate (11-20) & 37 & 30.8 & 9.08 & 3.08 \\
\hline \multirow[t]{3}{*}{ Practiced cropping intensity (\%) } & - & $200-300$ & Low (200-233) & 38 & 31.7 & & \\
\hline & & & Medium (234-266) & 55 & 45.8 & 246.87 & 23.17 \\
\hline & & & High (267-300) & 27 & 22.5 & & \\
\hline
\end{tabular}

Note: Pos. $=$ Possible, Obs $=$ Observed and SD $=$ Standard Deviation 
Table 2. Contribution of farming enterprises towards household food security

\begin{tabular}{|c|c|c|c|c|c|c|}
\hline \multicolumn{2}{|l|}{ Range (\%) } & \multicolumn{3}{|l|}{ Respondents } & \multirow{2}{*}{ Mean } & \multirow{2}{*}{$\begin{array}{l}\text { Standard } \\
\text { Deviation }\end{array}$} \\
\hline Possible & Observed & Category & No. & $\%$ & & \\
\hline \multirow{3}{*}{ Unknown } & \multirow{3}{*}{$10.03-96.45$} & Low $(<33)$ & 32 & 26.7 & \multirow{3}{*}{44.78} & \multirow{3}{*}{17.97} \\
\hline & & Medium (33-67) & 74 & 56.6 & & \\
\hline & & High $(>67)$ & 14 & 16.7 & & \\
\hline
\end{tabular}

Small farmers operated various farming enterprises, such as rice, wheat, jute, potato, fisheries, fruits, spices etc. in their small holdings. Investigating the contribution of these farming enterprises of the small farmers was the main focus of the present study. From the table 2, it was found that the range of contribution varied from 10.03 to $96.45 \%$ with an average of $44.78 \%$ and standard deviation $17.97 \%$. Among the respondent small farmers, more than half (56.6\%) received medium level of contribution while 26.7 and $16.7 \%$ of them received low and high level of contribution respectively from their farming enterprises to the household food security.

Table 3. Contribution of the major farming enterprises of the small farmers

\begin{tabular}{lcccc}
\hline \multirow{2}{*}{ Farming enterprises } & \multicolumn{2}{c}{ Range (\%) } & Mean & SD \\
\cline { 2 - 4 } Crops & Possible & Observed & 41.70 & 17.22 \\
Livestock & Unknown & $8.74-96.14$ & 2.15 & 3.50 \\
Fisheries & Unknown & $0.01-23.86$ & 0.47 & 1.02 \\
Fruits & Unknown & $0.00-7.03$ & 0.46 & 0.61 \\
\hline
\end{tabular}

Overall contribution of the farming enterprises of the small farmers has been partitioned where crop sector alone contributed $41.70 \%$ towards the household food security followed by livestock $2.15 \%$, fisheries $0.47 \%$ and fruits $0.46 \%$ (Table 3). Information presented in the Table 4 reveal that most of the farm produces $(81.57 \%$ ) are sold out for other household purposes. More than $97.73 \%$ of the outputs of livestock, fisheries (93.27) and fruit sectors (91.92\%) were sold out. Crops were sold out comparatively lower $(80.52 \%)$ than other produces. Among the crops, rice is hardly sold out because the small farmers of the study area were not able to produce rice according to their family needs. The other farm produces were mainly sold out to purchase rice, fish, meat and other household necessities.

Table 4. Average calorie productions, consumption and sold out proportion

\begin{tabular}{c|c|c|c}
\hline Farming enterprises & Production (Kcal) & Consumption (Kcal) & $\begin{array}{c}\text { Sold out } \\
\text { (Kcal) }\end{array}$ \\
\hline Crops & 1364.7 & $265.9(19.48 \%)$ & $1098.81(80.52 \%)$ \\
Livestock & 68.55 & $1.56(2.27 \%)$ & $66.99(97.73 \%)$ \\
Fisheries & 14.90 & $1.03(6.73 \%)$ & $13.90(93.27 \%)$ \\
Fruits & 15.23 & $1.23(8.08 \%)$ & $14.00(91.92 \%)$ \\
\hline Total & 1463.4 & $269.7(18.43 \%)$ & $1193.70(81.57 \%)$ \\
\hline
\end{tabular}

\section{Relationships between Independent and Dependent variables \\ Age and contribution of farming enterprises : The} correlation coefficient between age of the small farmers and the contribution of their farming enterprises towards the household food security was 0.118 where the computed ' $r$ ' value was nonsignificant. Hence, the concerned null hypothesis could be accepted. Thus, it could be said that age of the respondents could not significantly influence their achievement of household food security from their farming enterprises. Moreover, age was positively correlated with family size, annual dietary needs of the family, credit received and practiced cropping intensity. The former two variables influenced negatively on the contribution of farming enterprises towards the household food security but the later positively. Eventually, the effect of age on the contribution was not important as contradictory influences of the related variables.

Education and contribution of farming enterprises : The correlation coefficient showed positively non significant between education of the small farmers and the contribution of their farming enterprises to the household food security was 0.016 (Table 5). So, the concerned null hypothesis could be accepted. It could be concluded that education of the respondents could not influence their achievement of household food security from their farming enterprises. The majority of the small farmers had illiterate to primary level of education. In addition, among the farmers $36.7 \%$ were educated up to class ten. 
Family size and contribution of farming enterprises : Their correlation coefficient value was -0.480 based on the computed ' $r$ ' value was negatively significant. Hence, the concerned null hypothesis could not be rejected. Thus, it could be depicted that family size of the respondents greatly influenced their achievement of household food security from their farming enterprises. Amount of calorie needed by the family increases with the increase of the number of family members where family size decreased with the increase of family requirements. Therefore, it seems to be logical that contribution of farming enterprises was decreased with the increase of family size.

Annual dietary needs of the family and contribution of farming enterprises : Their correlation coefficient was $r=-0.514$ where computed ' $r$ ' value point towards the significant negative relationship between hem. So, the concerned null hypothesis could be rejected. It could be concluded that annual dietary needs of the family of the respondents was an important indicator for the assessment of the contribution of farming enterprises. Household food security has a direct linear relationship with the annual dietary needs of the family. Therefore, as the annual dietary needs of the family increased, the contribution of the farming enterprises considerably decreased.

Farm size and contribution of farming enterprises: The correlation coefficient between them was 0.421 where computed ' $r$ ' value was positively significant. Hence, the concerned null hypothesis could be rejected. Greater land areas obviously facilitated to practice more number and quantity of farming enterprises. In this way the simple logic behind the present findings can easily be traced out.

Daily time allocation in farm works and contribution of farming enterprises: Table 5 indicates that the correlation coefficient between daily time allocation and contribution of their farming enterprises was 0.016 while computed ' $r$ ' value, the relationship between these two variables showed positively non-significant. So, the concerned null hypothesis could be accepted. It could be concluded that daily time allocation in farm work of the small farmers was not dominant to their achievement of household food security from their farming enterprises.

Table 5. Relations between dependent and independent variables

\begin{tabular}{lc}
\hline \multicolumn{1}{c}{ Characteristics of the small farmers } & 'r' value with 118 d.f. \\
\hline Age & -0.118 \\
Education & 0.016 \\
Family size & $-0.480^{* *}$ \\
Annual dietary needs of the family & $-0.514^{* *}$ \\
Farm size & $0.421^{* *}$ \\
Annual family income & $0.392^{* *}$ \\
Credit received & -0.072 \\
Daily time allocation in farm work & 0.016 \\
Exposure to farming information & 0.039 \\
Practiced cropping intensity & $-0.234^{*}$ \\
\hline
\end{tabular}

** Significant at $1 \%$ level of probability

* Significant at the $5 \%$ level of probability

The extent of problems faced by the small farmers in achieving household food security in terms of Problem Facing Index (PFI) along with their rank order based on the PFI values have been presented in Table 6 and 7. Data furnished in the table indicate that the problem which ranked in the first was 'Inadequate land for farming' followed by second ranked 'inadequate training facilities' and third ranked 'lack of contact with communication media'. 'Noncooperation of family members' was the least important problem among those faced by the small farmers in achieving household food security.

Table 6. Problems faced by small farmers in achieving household food security

\begin{tabular}{|c|c|c|c|c|c|c|}
\hline \multicolumn{2}{|c|}{ Range of score } & \multicolumn{3}{|c|}{ Respondents } & \multirow[b]{2}{*}{ Mean } & \multirow[b]{2}{*}{ Std. Dev. } \\
\hline Possible & Observed & Category & No. & $\%$ & & \\
\hline \multirow{3}{*}{$0-30$} & & Low $(\leq 10)$ & 3 & 2.5 & \multirow{3}{*}{15.07} & \multirow{3}{*}{2.46} \\
\hline & $5-20$ & Medium (11-20) & 117 & 97.5 & & \\
\hline & & High $(>20)$ & 0 & 0 & & \\
\hline Total & & & 120 & 100 & & \\
\hline
\end{tabular}


Table 7. Ranking of problems according to descending order

\begin{tabular}{rlr}
\hline Rank order & Problems & PFI \\
\hline 1 & Inadequate land for farming & 358 \\
2 & Inadequate training facilities & 336 \\
3 & Lack of contact with communication media & 291 \\
4 & Insufficient credit & 271 \\
5 & Lack of money & 202 \\
6 & Lack of time & \\
7 & Lack of knowledge of different aspects of farming enterprises \\
8 & Lack of personal interest & 96 \\
9 & Social and religious restriction & \\
10 & Non-cooperation of family members & \\
\hline
\end{tabular}

\section{Conclusion}

Findings of the study and the logical interpretations of their meanings in the light of other relevant facts prompted the researcher to draw the following conclusions:

- Findings indicate that the highest proportion of the respondents $(56.6 \%)$ were in medium category regarding the achievement of their household food security. Moreover, 55.22\% annual dietary needs remained unsatisfied. So, there was greater scope to foster the contribution of farming enterprises towards household food security with a special emphasis on the crop sector. Among the selected characteristics of the small farmer age, family size, annual dietary needs of the family, credit received and practiced cropping intensity had negative relationship with the contribution of farming enterprises towards household food security. In addition, family size and family dietary need are directly related. Therefore, small family size is desirable to attain more contribution from farming enterprises towards household food security.

- Farm size and annual family income were positively correlated with the contribution of farming enterprises towards household food security. Larger farm size leads to earn higher annual income. Eventually, farm size and family income were important indicators of the contribution of farming enterprises towards household food security.

- $\quad$ Though practiced cropping intensity showed negative relationship with the contribution of farming enterprises towards household food security, it could be helpful to increase the level of contribution of farming enterprises if cropping intensity could be increased by the small farmers having comparatively larger farm size. Most of the farmers faced medium level of different problems in achieving household food security. Minimum level of problem is always expected to achieve desirable outputs.

\section{References}

Akter, T. 2003. Participation of Women in Income Generating Activities (IGA) of SUS. M.S. (Ag. Ext. Ed.) Thesis, Dept. of Agricultural Extension Education, Bangladesh Agricultural University, Mymensingh, Bangladesh

Amin, M.R. 2004. Participation of Rural Women in Selected Aquaculture Activities. M.S. (Ag. Ext. Ed.) Thesis, Dept. of Agricultural Extension Education, Bangladesh Agricultural University, Mymensingh, Bangladesh.

Azad, M.A.K. 2003. Participation of Women in Decision making Regarding Farming Activities in two Selected Villages of Patuakhali District. M.S. (Ag. Ex. Ed.) Thesis, Dept. of Agricultural Extension Education, Bangladesh Agricultural University, Mymensingh, Bangladesh

Dulayapach, P. 1990. Prospects for Rural Women's Contribution to Sustainable Food Security. In: Anonymous (ed). 2002. Role of Rural Women in Food Security in Asia and the Pacific. Asian Productivity Organization, Tokyo, Japan

FAO.1995.World Agricultural towards 2010: An FAO Study. Rome: Food and Agriculture Organization.

Hasan, M.K. 2006. Participation in Farming Activities by Conventional and Organic Farmers. M.S. (Ag. Ex. Ed.) Thesis, Dept. of Agricultural Extension Education, Bangladesh Agricultural University, Mymensingh, Bangladesh

Khan, M.A.S. 2004. Farmers' Participation in Farm and Community Level Activities in Sailokupa Upazila under Jhenaidah District. M.S. (Ag. Ext. Ed.) Thesis, Dept. of Agricultural Extension Education, Bangladesh Agricultural University, Mymensingh, Bangladesh.

Kleiner, S. 2006. Questions and Answers about Nutrition. Microsoft Encarta 2006 (DVD). Redmond, WA: Microsoft Corporation. 